\title{
Refining Micropore Capacity of Activated Carbon Derived from Coconut Shell via Deashing Post- Treatment
}

\author{
Kit Ling Chin, ${ }^{a *}$ Chuan Li Lee, ${ }^{\text {a }}$ Paik San H'ng, ${ }^{\text {a,b* }}$ Umer Rashid, ${ }^{\mathrm{c}}$ Md Tahir Paridah, ${ }^{\mathrm{a}}$ \\ Pui San Khoo, ${ }^{a}$ and Mariusz Maminski ${ }^{\mathrm{d}}$
}

\begin{abstract}
The discovery of new methods to control porosity and microarchitecture may lead to the refinement of carbon materials from lignocellulose as advanced functional materials. However, the high ash content on the surface of lignocellulosic biomass reduces the surface area and adsorption properties of the activated carbon. This study presents a novel approach, using a deashing post-treatment as the pore generator, to increase the quality of the activated carbon. The micropore capacity was improved by deashing post-treatment with distilled water, where $80 \%$ of the total pore ratio of the activated carbon was occupied with micropores. Ultrasonic treatment was able to penetrate deeper into the structure of coconut shell activated carbon, creating cavities and pores, thus increasing the surface area. Understanding the effects of these new controlling methods on pore refinement can elucidate the microporous fabrication of other activated carbons from high ash-content lignocellulosic biomass.
\end{abstract}

Keywords: Micropores; Coconut shell; Deashing post-treatment; Surface area; Activated carbon

Contact information: a: Institute of Tropical Forestry and Forest Products, Universiti Putra Malaysia, 43400 UPM Serdang, Selangor, Malaysia; b: Faculty of Forestry and Environmental, Universiti Putra Malaysia, 43400 UPM Serdang, Selangor, Malaysia; c: Institute of Advance Technology, Universiti Putra Malaysia, 43400 UPM Serdang, Selangor, Malaysia; d: Faculty of Wood Technology, Warsaw University of Life Sciences-SGGW,159 Nowoursynowska Street, 02-787 Warsaw, Poland;

*Corresponding authors: ngpaiksan@gmail.com; kitling.chin419@gmail.com

\section{INTRODUCTION}

The demand for activated carbon is increasing globally, approaching an estimated USD 8.12 billion in 2021, while in terms of volume the overall market is projected to reach 3,860 kilotons (Tiwari 2017). Most commercial activated carbon production relies on coal, as it is the most commonly used raw material (Robinson et al. 2001; Saleem et al. 2019). Because coal mining adversely affects the global environment and ecosystem, the use of coal is being reduced (Singh 2013; Goswami 2015). Therefore, the amount of highly modifiable carbon materials should be increased to meet the demand. Lignocellulosic biomass is a great alternative to replace coal for activated carbon production. The carbon source, preparation conditions such as temperature and atmosphere, and preparation methods affect the structure and properties of the carbon material (Hamasaki et al. 2019). The discovery of new methods to control the porosity and microarchitecture has the potential to lead to the refinement of carbon resources from lignocellulose as advanced functional materials.

The high-density and rigidity of nutshell biomass makes it a promising modifiable material for producing activated carbons with microporous structure (Mesa and Spokas 
2016). Hence, coconut shell (CS) was chosen as the carbon material for surface refinement and structure modification in this study. One new method to refine carbon resources as advanced functional materials is the two-stage continuous physical activation via air and $\mathrm{N}_{2}$ on high-ash biomass pretreated with phosphoric acid $\left(\mathrm{H}_{3} \mathrm{PO}_{4}\right)$. This process significantly increases the quality of the activated carbon (Lee et al. 2018). However, the activated carbon exhibits a high ash content and possesses a typical mesoporous structure with moderately high specific surface area. The same results were presented in other research (Lee et al. 2017, 2019; Tsai and Jiang 2018). A huge percentage of ash blocks the surface entrance to the micropores of the activated carbon and prevents the application of the carbon material. CS tends to have a high ash content (above 15\%) with a low ashmelting temperature (López et al. 2010). The amount of ash content in the biomass feedstock negatively correlates with the specific surface area of the produced activated carbon (Ahiduzzaman and Islam 2016). This is due to the fusion of molten ash, which clogs the pores of the carbon during the high temperature conversion process, thereby decreasing accessible surface area (Ronsse et al. 2013). All of these factors are directly limiting the industrial application and usage of activated carbon derived from lignocellulosic biomass with a naturally high ash content.

The usage and performance of a carbon material are determined by its surface area, pore size, and surface properties. Poor characteristics of pore size and surface properties are the main limitations to the adsorption capacity and are extremely difficult to control in commercial carbons. Controlled pore size and pore size distribution with specific surface characteristics are necessary for specific end use because the performance of porous carbon depends strongly on pore structure as well as surface characteristics. The success of biomass conversion into activated carbon with high microporous structure depends on two main factors: creation of high surface area through the development of micropores and removal of ash content during the activation process. Li et al. (2016) reported that increases in the specific surface area and pore volume were consistent with decreasing ash content. Thus, deashing is a crucial process for the conversion of lignocellulosic biomass into advanced functional activated carbon. Deashing offers the possibility of modifying and controlling the porous texture of the activated carbons by varying the preparation conditions and techniques.

The kinetics of removing the ash forming element in distilled water and $\mathrm{H}_{3} \mathrm{PO}_{4}$ under conventional stirring was selected as the topic for this study. Deashing treatments by soaking the biomass or char in hot dilute acid or hot water have been reported (Pandey et al. 2015; Lee et al. 2018, 2019). The results provide insights into the influence of water in removing ash content from CS. However, some lignocellulosic biomass consists of higher non-water soluble elements that cannot be easily removed by water. Thus, washing with dilute acid has been developed. Phosphoric acid $\left(\mathrm{H}_{3} \mathrm{PO}_{4}\right)$, hydrochloric acid $(\mathrm{HCl})$, and hydrofluoric acid (HF) are the most common agents reported to efficiently eliminate mineral matter and other impurities from various types of lignocellulosic biomass (Hagemann et al. 2018; Li et al. 2020; Yacob and Al Swaidan 2012). Lignocellulosic biomass specimens that were impregnated with $\mathrm{HCl}$ and $\mathrm{HF}$ resulted in higher mesopore volume, while $\mathrm{H}_{3} \mathrm{PO}_{4}$ resulted in higher micropore volume (Jayaraman et al. 2017; Tan et al. 2017; Zhang et al. 2017). This is due to the milder reaction of $\mathrm{H}_{3} \mathrm{PO}_{4}$ on the biomass, which sufficiently unclogged the pores but had less damaging effects on the pore wall. Thus $\mathrm{H}_{3} \mathrm{PO}_{4}$, as a milder agent, was selected in this study to remove minerals that were initially clogging the pores of the activated carbon. As reported by Haykiri-Acma and Yaman (2019), $\mathrm{Na}, \mathrm{K}, \mathrm{Ca}, \mathrm{Mg}$, and Fe were effectively removed by $\mathrm{H}_{3} \mathrm{PO}_{4}$ treatment. 
However, the success of the deashing post-treatment greatly depends on the raw materials and deashing conditions. A few studies have indicated that the extraction of ash content by different deashing techniques differs considerably for different sources of materials (Chin et al. 2015; Sana et al. 2018). Reaction temperature should also be considered because the prolonged exposure to severe deashing conditions may result in drastic reduction of pore wall thickness and eventually lead to the collapse of pores.

Ultrasonic treatment was selected as the potential deashing post-treatment in this study. Ultrasonic waves intensify deashing, extraction, ionic exchange, and other hydrometallurgical processes (Wang et al. 2017). No similar work has been reported using ultrasonic post-treatment to modify and refine surface structure of activated carbon derived from CS. The proper selection of deashing treatments needs to be evaluated on a case-bycase basis, as it highly depends on the ash removal effectiveness of different treatment method, and the effect of these treatments leading to pore size and absorption capabilities of the activated carbon.

The overall objective of this work was to study the effects of these deashing techniques (water, $\mathrm{H}_{3} \mathrm{PO}_{4}$, and ultrasonic) on pore refinement and surface modification of activated carbons from high ash-content lignocellulosic biomass. The study determined the impact of deashing process parameters, including the types of deashing technique and deashing temperature on the adsorbent characteristic of activated carbon derived from CS. Understanding the effects of these deashing methods on pore refinement can shed light on the microporous fabrication of other lignocellulosic-based activated carbon for the use as advanced functional materials with dynamically controlled micropore size and tunable surface properties.

\section{EXPERIMENTAL}

\section{Material}

CS was collected, cleaned, and dried in an oven at $105^{\circ} \mathrm{C}$ for $48 \mathrm{~h}$. The dried raw materials were crushed and sieved to 2 - to 5-mm size range.

\section{Methods}

Preparation of coconut shell activated carbon samples

A specified mass of the dried CS was impregnated with $30 \%$ phosphoric acid $\left(\mathrm{H}_{3} \mathrm{PO}_{4}\right)$ with an impregnation mass ratio of $1: 1$ at $80{ }^{\circ} \mathrm{C}$ for $2 \mathrm{~h}$. The pretreated particles were filtered and washed with distilled water. The washed pretreated particles were dried at $105{ }^{\circ} \mathrm{C}$ for $48 \mathrm{~h}$. Physical activation was performed in a horizontal laboratory tube furnace. For two-stage continuous physical activation, the $\mathrm{H}_{3} \mathrm{PO}_{4}$ pretreated samples were activated continuously in two-stages with different gas carriers, air and $\mathrm{N}_{2}$. The activation temperature was set at $600{ }^{\circ} \mathrm{C}$ for both activation stages with the heating rate of $3{ }^{\circ} \mathrm{C} / \mathrm{min}$. For " $\mathrm{N}_{2}>$ Air" activation, the pretreated samples were activated in $\mathrm{N}_{2}$ (flow rate $=100$ $\mathrm{mL} / \mathrm{min}$ ) for $75 \mathrm{~min}$ before undergoing the air activation (flow rate $=100 \mathrm{~mL} / \mathrm{min}$ ) for 30 min. The method on the preparation of CS activated carbon was selected based on the optimum condition from the authors' previous study (Lee et al. 2018), for which the CS activated carbon produced achieved the highest BET surface area value.

\section{Deashing post-treatment}

Three different deashing post-treatments: (1) soaked in distilled water; (2) soaked 
in $30 \%$ of $\mathrm{H}_{3} \mathrm{PO}_{4}$ solution; or (3) ultrasonic treatment were selected in this study. The activated carbon samples were impregnated with distilled water or phosphoric acid with an impregnation ratio in mass of $1: 1$ at three different temperatures (room temperature (RT), 60 , and $100{ }^{\circ} \mathrm{C}$ ), respectively for $2 \mathrm{~h}$. For ultrasonic post-treatment, the activated carbon samples (20 g per batch) were placed in an ultrasonic oscillator at different temperature $\left(40,60\right.$, and $\left.80{ }^{\circ} \mathrm{C}\right)$. Ultrasonic post-treatment was carried out at a power of $2 \mathrm{~kW}$ and a frequency of $20 \mathrm{kHz}$ for a duration of $2 \mathrm{~h}$. Once the deashing solution was removed, the sample was washed with ambient temperature distilled water $\left(25\right.$ to $\left.28{ }^{\circ} \mathrm{C}\right)$ using a solid: liquid ratio of $1: 100(\mathrm{w} / \mathrm{v})$, by removing the liquid phase by centrifugation. The washed samples were dried at $105{ }^{\circ} \mathrm{C}$ for $48 \mathrm{~h}$ and then stored in desiccators. Each of the nine treatments ( 3 deashing post-treatments $\mathrm{x} 3$ deashing temperatures) was replicated 5 times.

\section{Test standards}

The experimental methods used for the testing process and the calculation for the physiochemical properties of bioadsorbent were according to Lee et al. (2017). Methylene blue and iodine number of activated carbon were determined according to the standard method; JIS K 1470-1991 and ASTM D4607-94, respectively. The specific surface area was determined by the Brunauer Emmett-Teller (BET) method. In order to analyse the morphology of the activated carbon, the sample prepared at the optimum condition was examined using Scanning Electron Microscope (SEM). A Thermo Scientific ARL QUANT'X Energy Dispersive X-ray Fluorescence (EDXRF) machine was used for the elemental analysis.

\section{Data analysis}

Statistical analyses were carried out using the statistical package SPSS for Windows, version 16.0 (SPSS, Chicago, IL, USA). This was used to evaluate the data of adsorption properties of activated carbon for analysis of variance (ANOVA) at $95 \%$ confident level $(\mathrm{P} \leq 0.05)$. The Tukey-Kramer multiple comparison test was applied to analyse the differences of the treatment effects when significance was observed. The effects were considered not statistically significant when the $\mathrm{p}$-value was higher than 0.05 at the $95 \%$ confidence level.

\section{RESULTS AND DISCUSSION}

\section{Effect of Deashing Treatments on the Physicochemical Properties of the Activated Carbon}

The properties of CS activated carbon derived from deashing post-treatment and its physiochemical properties are summarized in Table 1. The two-way ANOVA (deashing technique and temperature) revealed significant differences of deashing technique $(\mathrm{p}<0.01)$, temperature $(\mathrm{p}<0.01)$ and interaction between two factors $(\mathrm{p}<0.01)$ on physiochemical properties of the post-treated activated carbon.

The CS activated carbon post-treated with ultrasonic method demonstrated the lowest mass yield. The weight loss of CS activated carbon prepared under ultrasonic posttreatment was $79.1 \%$. The high amount of mass loss is caused by the mechanical effect of ultrasound, which accelerated the motion of suspended particles leading to high mass transfer from the activated carbon (Wang et al. 2017). The activated carbon from distilled water resulted with the least mass loss. The minimal mass loss value reflected that the 
treatment with distilled water is mild and caused very minimal degradation on the activated carbon. As listed in Table 1, the mass loss increased with the increasing temperature. The increasing temperature contributes to the reduction in external mass transfer and facilitates a higher mass loss for the activated carbon.

Table 1. Effect of Deashing Treatments on the Physiochemical Properties of the CS Activated Carbon.

\begin{tabular}{|c|c|c|c|c|c|c|c|}
\hline Sample & $\begin{array}{l}\text { Temp } \\
\left({ }^{\circ} \mathrm{C}\right)\end{array}$ & $\begin{array}{l}\text { Yield } \\
(\%)\end{array}$ & $\begin{array}{c}\text { Bulk } \\
\text { Density } \\
\left(\mathrm{g} / \mathrm{cm}^{3}\right)\end{array}$ & $\mathrm{pH}$ & $\begin{array}{c}\text { Ash } \\
\text { Content } \\
(\%)\end{array}$ & $\begin{array}{c}\text { Volatile } \\
\text { Content } \\
(\%)\end{array}$ & $\begin{array}{c}\text { Carbon } \\
\text { Content } \\
(\%)\end{array}$ \\
\hline Raw material & - & - & 0.542 & 6.3 & 1.17 & 9.24 & 88.85 \\
\hline Activated carbon & - & 35.31 & 0.540 & 7.5 & 5.42 & 10.48 & 83.17 \\
\hline \multirow{3}{*}{$\begin{array}{l}\text { Distilled } \\
\text { water }\end{array}$} & RT & $33.70^{a}$ & $0.530^{\mathrm{ab}}$ & $7.2^{\mathrm{a}}$ & $2.51^{b}$ & $7.56^{\mathrm{c}}$ & $89.82^{b}$ \\
\hline & 60 & $32.65^{b}$ & $0.528^{\mathrm{a}}$ & $7.3^{\mathrm{b}}$ & $2.68^{\mathrm{c}}$ & $6.24^{\mathrm{a}}$ & $91.05^{\mathrm{a}}$ \\
\hline & 100 & $29.22^{c}$ & $0.527^{a}$ & $7.5^{\mathrm{c}}$ & $4.31^{\mathrm{e}}$ & $6.21^{a}$ & $89.46^{c}$ \\
\hline \multirow[t]{3}{*}{$\mathrm{H}_{3} \mathrm{PO}_{4}$} & RT & $27.06^{d}$ & $0.557^{d}$ & $2.2^{\mathrm{gh}}$ & $8.62^{\mathrm{g}}$ & $9.03^{h}$ & $82.00^{9}$ \\
\hline & 60 & $24.55^{\mathrm{e}}$ & $0.598^{\mathrm{e}}$ & $2.3^{9}$ & $9.34^{\mathrm{h}}$ & $8.90^{\dagger}$ & $81.67^{h}$ \\
\hline & 100 & $23.87^{f}$ & $0.613^{f}$ & $2.2^{h}$ & $10.88^{i}$ & $8.85^{\mathrm{e}}$ & $80.22^{i}$ \\
\hline \multirow[t]{3}{*}{ Ultrasonic } & 40 & $22.72^{\mathrm{g}}$ & $0.536^{c}$ & $4.5^{\mathrm{d}}$ & $2.23^{a}$ & $8.97^{9}$ & $88.39^{\mathrm{e}}$ \\
\hline & 60 & $21.14^{\mathrm{h}}$ & $0.534^{\mathrm{bc}}$ & $4.2^{\mathrm{e}}$ & $2.78^{d}$ & $8.54^{\mathrm{d}}$ & $89.58^{d}$ \\
\hline & 80 & $20.94^{\mathrm{h}}$ & $0.530^{\mathrm{ab}}$ & $4.0^{f}$ & $4.64^{\dagger}$ & $7.44^{\mathrm{b}}$ & $87.90^{f}$ \\
\hline \multicolumn{2}{|l|}{$p$-value } & $<0.001$ & $<0.001$ & $<0.001$ & $<0.001$ & $<0.001$ & $<0.001$ \\
\hline
\end{tabular}

Note:

Means followed by the same letters (superscript) in the same column are not significantly different at $\mathrm{P} \leq 0.05$ according to Tukey's test.

The $p$-values reveal the strength of differences between factors (deashing technique $x$ temperature) on the physiochemical properties of the CS activated carbon.

Distilled water and ultrasonic post-treatment gradually reduced the bulk density of the activated carbon. The bulk density for activated carbon prepared via ultrasonic and distilled water post-treatment was comparable to commercial activated carbon. The typical bulk density for activated carbon is 0.45 to $0.55 \mathrm{~g} / \mathrm{cm}^{3}$ (Yenisoy-Karakaş et al. 2004). The bulk density decreased almost linearly with increasing temperature during distilled water and ultrasonic post-treatment. Bulk density decreased with progression of activation due to porosity development (Lima and Marshall 2005; Abechi et al. 2013).

Table 1 shows that the activated carbon from distilled water treatment slightly reduce the $\mathrm{pH}$ of the activated carbon to near-neutral. Distilled water was able to remove adhering dust, salt, and parts of metal impurities, which includes alkaline metal from the activated carbon (Kilpimaa et al. 2014; Liu et al. 2018). The $\mathrm{pH}$ of adsorbent, which is near to neutral, is useful in all classes of dye wastewater treatment and drinking water purification (Baseri et al. 2012). The carbon prepared under ultrasonic treatment was slightly acidic. This may due to the ultrasonic cavitation generated in the solution and causes micro-bubbles during ultrasound treatment. When micro-bubbles collapse, high energy is released and converted to high pressure and high temperature, and can generate both physical and chemical effects (Kawasaki et al. 2007; Koda et al. 2009; Li et al. 2018). The chemical reaction from ultrasonication shifted the activated carbon to acidic form.

An increasing trend of ash content in the range of 8.62 to $10.88 \%$ occurred on the $\mathrm{CS}$ activated carbon prepared under $\mathrm{H}_{3} \mathrm{PO}_{4}$ post-treatment. This result indicated that some chemical remained in the activated carbon after washing (László et al. 1997; Anisuzzaman et al. 2015). Although elements such as $\mathrm{Na}, \mathrm{K}, \mathrm{Ca}, \mathrm{Mg}$, and $\mathrm{Fe}$ could be effectively 
removed by $\mathrm{H}_{3} \mathrm{PO}_{4}$ treatment, formation of phosphorus containing new phases caused to increase in ash yield (Haykiri-Acma and Yaman 2019). The entrapped polyphosphates in the activated carbon after $\mathrm{H}_{3} \mathrm{PO}_{4}$ post-treatment contributed to a slight increase of ash content in CS activated carbon and gave the final product with acidic character. Deashing via distilled water was effective in removing most of the impurities from the activated carbon. The reduction of impurities led to the lowest ash content compared to other deashing techniques, as shown in Table 1. The ash is a non-carbon material, which is usually mineral elements that are not attached to the surface of the carbon. It can influence the adsorptive capacity of the activated carbon, as it is linked directly to the pore structure of the activated carbon (Anisuzzaman et al. 2015). In other words, when the value of the ash content decreases, the efficiency and adsorptive capacity of the prepared activated increase.

The positive effects of the deashing were counteracted by the amount of ash and volatiles content left on the activated carbon. The volatile content was reduced with the increasing deashing temperature. A higher elimination rate of volatile contents and higher development rate of pore structure accrued with thermal treatment. The CS activated carbon achieved the lowest volatile content when post-treated with $100{ }^{\circ} \mathrm{C}$ distilled water.

The decreasing of volatile content directly increased the fixed carbon content of the CS activated carbon. The highest fixed carbon content was at the rate of $91.0 \%$ for CS activated carbon. Thus, $60{ }^{\circ} \mathrm{C}$ was the optimum temperature for distilled water posttreatment by virtue of maximum fixed carbon content and minimum ash content for CS activated carbon. Activated carbon obtained from this optimum condition was brittle, bright in colour, and light weight. These properties are the expected characteristics for activated carbon (Thwe et al. 2018).

\section{Effect of Deashing Treatments on the Adsorption Properties of the Activated Carbon}

The adsorption properties of activated carbon derived from post-treated CS are compiled in Table 2. The two-way ANOVA (deashing technique and temperature) revealed significant differences of deashing technique $(p<0.01)$, temperature $(p<0.01)$, and interaction between two factors $(\mathrm{p}<0.01)$ on the adsorption properties of the post-treated activated carbon.

According to Chen et al. (2011), the performances of activated carbons may be expressed in terms of yield, iodine, and methylene blue numbers. Methylene blue is used to measure the pore greater than $1.5 \mathrm{~nm}$ in diameter. The adsorption capacity of methylene blue on the activated carbon was dependent on $\mathrm{pH}$ values. Methylene blue (cationic dye) and acidic activated carbon tend to give positively charged ions when dissolved in water (Gerçel et al. 2008). Higher adsorption of methylene blue occurred on the activated carbon which are slightly acidic. This was due to the coexistence of a competitive adsorption with $\mathrm{H}^{+}$(Liu et al. 2017). However, with activated carbon of $\mathrm{pH}<3.5$, the number of negatively charged adsorbent decreased and the number of positively charged surface increased, which did not favour the adsorption of positively charged dye cation due to electrostatic repulsion (Nsami and Mbadcam 2013). Low methylene blue adsorption for $\mathrm{H}_{3} \mathrm{PO}_{4}$ posttreated carbon may also be caused by the presence of excess $\mathrm{H}^{+}$ions competing with dye cations for the available adsorption sites (Tadjarodi and Ghawami 2017). Through the adsorption properties results, the CS activated carbon post-treated with distilled water achieved the highest methylene blue adsorption, which was three times that of the activated carbon without post treatment. The results show that the produced activated carbon via 
distilled water post-treatment achieved neutral $\mathrm{pH}$ value. Activated carbon with neutral $\mathrm{pH}$ is favoured for accumulation of methylene blue dye (Baseri et al. 2012). As stated by Zulkania et al. (2018), the $\mathrm{pH}$ value of commercial activated carbon is neutral to slightly alkaline which is around 7.5 to 9 .

Table 2. Effect of Deashing Treatments on the Methylene Blue and lodine Adsorption of the CS Activated Carbon

\begin{tabular}{|c|c|c|c|}
\hline Sample & $\begin{array}{c}\text { Temperature } \\
\left({ }^{\circ} \mathrm{C}\right)\end{array}$ & $\begin{array}{c}\text { Methylene Blue } \\
\text { Adsorption }(\mathrm{mg} / \mathrm{g})\end{array}$ & $\begin{array}{c}\text { lodine Adsorption } \\
(\mathrm{mg} / \mathrm{g})\end{array}$ \\
\hline Raw material & - & 1.79 & 1.71 \\
\hline Activated carbon & - & 133.29 & 525.57 \\
\hline \multirow{2}{*}{$\begin{array}{c}\text { Distilled } \\
\text { water }\end{array}$} & $\mathrm{RT}$ & $374.25^{\mathrm{e}}$ & $602.83^{\mathrm{b}}$ \\
\cline { 2 - 4 } & 60 & $409.62^{\mathrm{a}}$ & $627.97^{\mathrm{a}}$ \\
\cline { 2 - 4 } & 100 & $369.89^{\mathrm{f}}$ & $577.70^{\mathrm{d}}$ \\
\cline { 2 - 4 } & $\mathrm{RT}$ & $129.45^{\mathrm{g}}$ & $280.77^{\mathrm{g}}$ \\
\cline { 2 - 4 } $\mathrm{H}_{3} \mathrm{PO}_{4}$ & 60 & $123.55^{\mathrm{h}}$ & $261.22^{\mathrm{h}}$ \\
\cline { 2 - 4 } & 100 & $119.96^{\mathrm{i}}$ & $203.51^{\mathrm{i}}$ \\
\hline \multirow{3}{*}{ Ultrasonic } & 40 & $397.06^{\mathrm{c}}$ & $560.02^{\mathrm{e}}$ \\
\cline { 2 - 4 } & 60 & $404.49^{\mathrm{g}}$ & $586.08^{\mathrm{c}}$ \\
\cline { 2 - 4 } & 80 & $392.70^{\mathrm{d}}$ & $554.43^{\mathrm{f}}$ \\
\hline \multicolumn{2}{|c|}{$\mathrm{p}$-value } & $<0.001$ & $<0.001$ \\
\hline
\end{tabular}

Note: Means followed by the same letters (superscript) in the same column are not significantly different at $\mathrm{P} \leq 0.05$ according to Tukey's test.

The $p$-values reveal the strength of differences between factors (deashing technique $x$ temperature) on the methylene blue and iodine adsorption of the CS activated carbon.

The iodine number indicates adsorption capacity, reflecting the amount of micropores with diameters larger than $1 \mathrm{~nm}$. Furthermore, iodine adsorption is used as an approximation of the surface area of adsorbent (Babatunde et al. 2016). The deashing posttreatment shows a great potential for the production of microporous activated carbon as a means to remove a range of pollutants from wastewater effluent. The highest iodine adsorption for CS activated carbon was attained when it post-treated with $60{ }^{\circ} \mathrm{C}$ distilled water. The increase in iodine adsorption capacity reflects the high degree of activation. Hot distilled water was able to remove impurities and ash in the adsorbent (Peng et al. 2018). Beyond that, the iodine adsorption of activated carbon decreased when the temperature was increased from 60 to $100{ }^{\circ} \mathrm{C}$. According to Arenas and Chejne (2004), high post-treatment temperatures have the tendency to halt the development of porous structures and to have a thinning effect on pore walls, which will cause the wall to collapse and eventually reduction in the adsorption capability with prolong treatment.

Activated carbon post-treated via $\mathrm{H}_{3} \mathrm{PO}_{4}$ obtained the lowest iodine adsorption. The low iodine adsorption for activated carbon produced by $\mathrm{H}_{3} \mathrm{PO}_{4}$ may also explain the deterioration of porous structure which probably caused by the destruction of the wall between adjacent micropores from the reaction with $\mathrm{H}_{3} \mathrm{PO}_{4}$ (Sych et al. 2012; Kumar and Jena 2016). The iodine adsorption capacity decreased with the increase in $\mathrm{H}_{3} \mathrm{PO}_{4}$ deashing temperature. This was attributed to the damage of the morphological structure of the activated carbon. The changes on the morphological structures are further explained below.

\section{Effect of Deashing Treatment on Surface Characteristics of Activated Carbon}

The surface characteristics of post-treated activated carbon are shown in Table 3, and the porosity ratio is illustrated in Fig. 1. The $\mathrm{N}_{2}$ adsorption isotherm of the sample is 
shown in Fig. 2. The microporous activated carbon were synthesized successfully using distilled water post-treatment. From the results of the porosity ratio (Fig. 1), distilled water post-treatment helped in producing micropore activated carbon. The entire $80 \%$ of the total pore ratio was occupied with micropores on CS activated carbons prepared via distilled water post-treatment. CS activated carbon achieved the highest surface area $\left(692 \mathrm{~m}^{2} / \mathrm{g}\right)$ when post-treated with $60{ }^{\circ} \mathrm{C}$ distilled water. The data of surface area is consistent with the results of the adsorption properties. Distilled water treatment plays a crucial role for the development of pore in CS activated carbon. Water evaporation eases the removal of chemicals from the micropores (Siipola et al. 2018). However, the surface area and pore volume were decreased when the temperature of the distilled water was increased from 60 ${ }^{\circ} \mathrm{C}$ to $100{ }^{\circ} \mathrm{C}$, indicating a non-linear development of the char porosity with the activation temperature. The reduction of the micropore surface area can be explained by the widening of the pores from micro size to meso, as shown in Table 3.

Table 3. Surface Characterization of the Activated Carbon via Deashing PostTreatment

\begin{tabular}{|c|c|c|c|c|}
\hline Sample & $\begin{array}{c}\text { Temperature } \\
\left({ }^{\circ} \mathrm{C}\right)\end{array}$ & $\begin{array}{c}\text { BET Surface Area } \\
\left(\mathrm{m}^{2} \mathrm{~g}^{-1}\right)\end{array}$ & $\begin{array}{c}\text { Micropore Pore } \\
\text { Volume } \\
\left(\mathrm{cm}^{3} \mathrm{~g}^{-1}\right)\end{array}$ & $\begin{array}{c}\text { Pore Size } \\
(\mathrm{nm})\end{array}$ \\
\hline Raw Material & - & 0.84 & 0.0013 & 6.30 \\
\hline Activated carbon & - & 479.17 & 0.05 & 0.62 \\
\hline Distilled water & $\mathrm{RT}$ & 486.78 & 0.17 & 2.26 \\
\cline { 2 - 5 } & 60 & 692.22 & 0.26 & 1.52 \\
\cline { 2 - 5 } & 100 & 338.52 & 0.13 & 2.53 \\
\hline \multirow{2}{*}{$\mathrm{H}_{3} \mathrm{PO}_{4}$} & $\mathrm{RT}$ & 210.33 & 0.07 & 43.17 \\
\cline { 2 - 5 } & 60 & 204.63 & 0.04 & 43.68 \\
\cline { 2 - 5 } & 100 & 177.79 & 0.07 & 43.95 \\
\hline \multirow{2}{*}{ Ultrasonic } & 40 & 482.24 & 0.14 & 8.24 \\
\cline { 2 - 5 } & 60 & 415.30 & 0.18 & 10.05 \\
\cline { 2 - 5 } & 80 & 259.40 & 0.10 & 15.19 \\
\hline
\end{tabular}

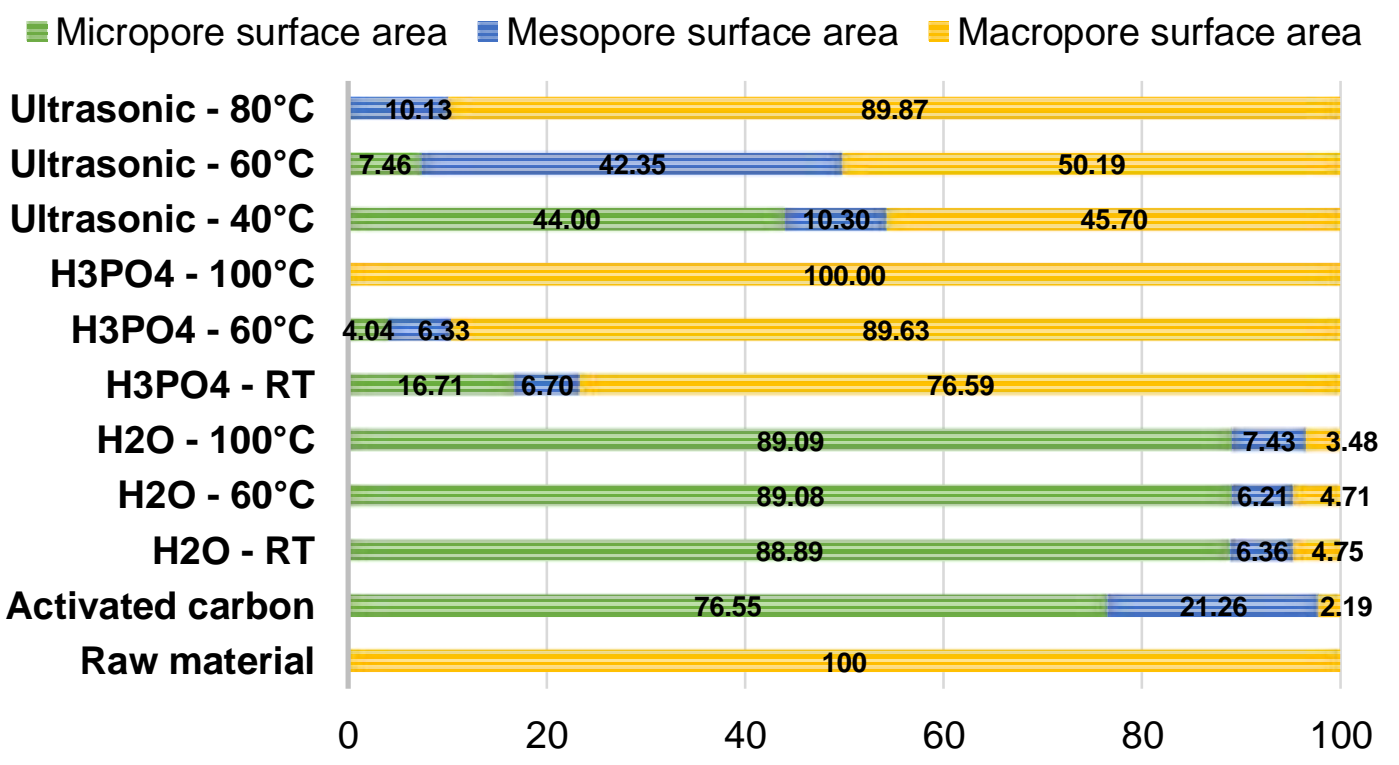

Fig. 1. The porosity ratio for the raw material, activated carbon, and post-treated activated carbon 
The surface characteristics of activated carbon were found to be temperaturedependent. The pore volumes of activated carbon increased with the increasing temperature to $60{ }^{\circ} \mathrm{C}$. Further increasing the temperature (higher than $60{ }^{\circ} \mathrm{C}$ ) showed a decreasing effect. This may because the higher temperature treatment removed some unburned carbon and degraded most of the micropores, which resulted in the reduction in surface area and pore volume (Wang et al. 2005). The result has marked that the distilled water posttreatment induced a higher surface area for CS activated carbon by the reduction the pore size.

The least efficient post-treatment was $\mathrm{H}_{3} \mathrm{PO}_{4}$. The large proportion of macropores (76\% to $100 \%$ ) resulted in a low surface area for activated carbons prepared via $\mathrm{H}_{3} \mathrm{PO}_{4}$ deashing. The addition of $\mathrm{H}_{3} \mathrm{PO}_{4}$ causing changes in the structure and adsorption properties of the activated carbon. $\mathrm{H}_{3} \mathrm{PO}_{4}$ causes degradation of organic material, which weakens the surface of activated carbon (Maulina and Iriansyah 2018). The pore wall thickness may be reduced to the point of disappearance, causing surface area and pore volumes to decrease (Sych et al. 2012; Siipola et al. 2018).
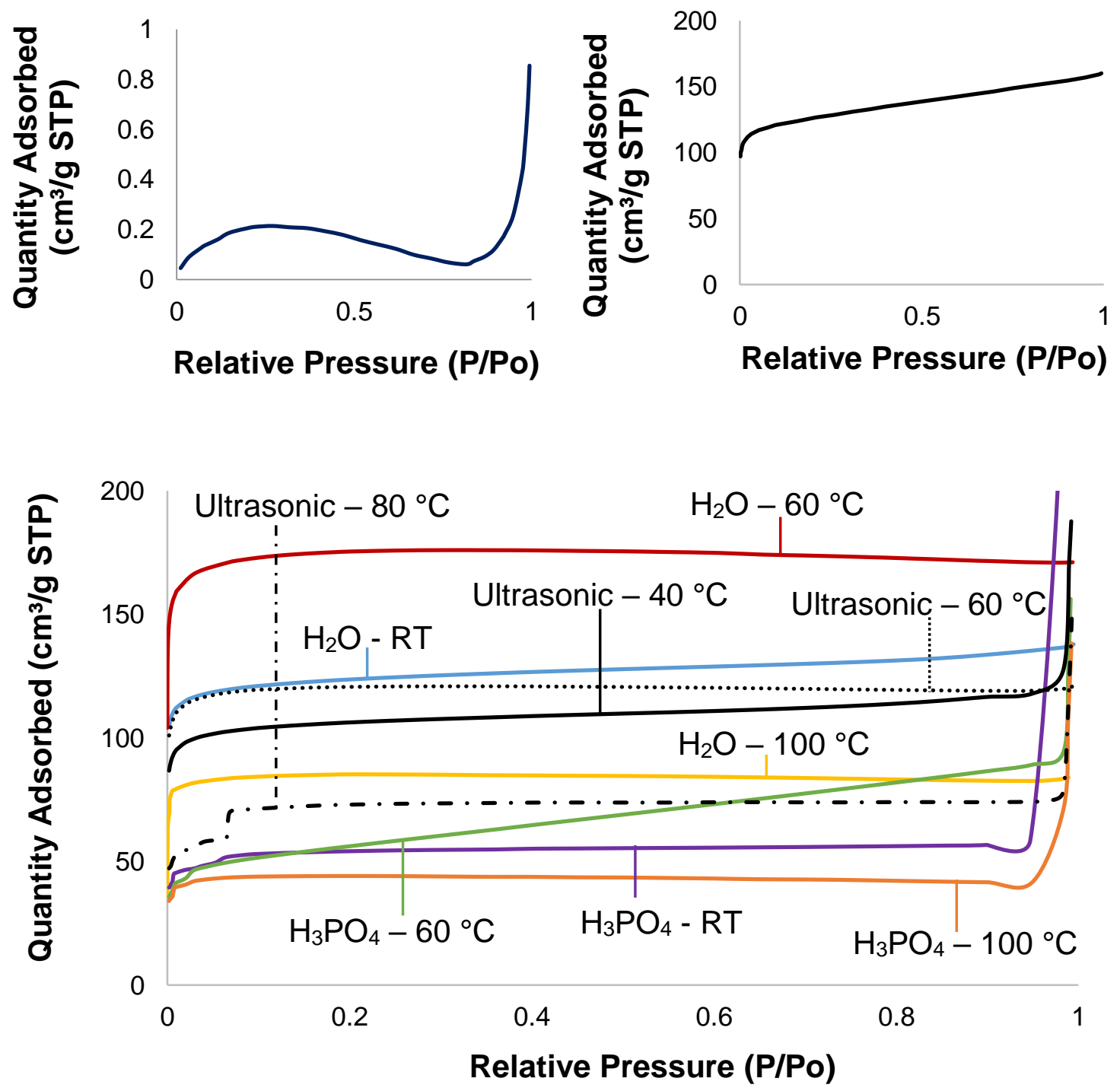

Fig. 2. $\mathrm{N}_{2}$ adsorption isotherm for (a) raw material and (b) activated carbon and (c) activated carbon derived from deashing treatment 
Figure 2a establishes the $\mathrm{N}_{2}$ adsorption isotherm acquired from the raw material $\mathrm{CS}$. The raw material CS conforms to type II isotherm, where B points out the zone where the monolayer becomes filled. This result indicated that CS is a nonporous or material with whole external surface. Figure $2 \mathrm{c}$ establishes the $\mathrm{N}_{2}$ adsorption isotherm acquired from the post-treated CS activated carbon. Activated carbons prepared via $\mathrm{H}_{3} \mathrm{PO}_{4}$ conformed to the type IV (b) isotherm. The initial part of the type-IV (b) isotherm for carbon represents micropore filling, and the slope of the plateau at high relative pressure is due to multilayer adsorption on non-microporous surfaces, i.e., in mesopores, in macropores, and on the external surface (Roquerol et al. 2013; Wang et al. 2013). CS activated carbon prepared via ultrasonic bath conformed to the type-IV (a) isotherm. This result indicates a significant microporous and mesoporous network system present in both activated carbons.

The CS activated carbon post-treated with distilled water conformed to the type I isotherm. This implies that the activated carbons can be categorized as microporous solids having relatively small external surfaces such as activated carbons, molecular sieve zeolites, and certain porous oxides. A steep uptake at very low $p / p^{\circ}$ is due to enhanced adsorbent-adsorptive interactions in narrow micropores (micropores of molecular dimensions), resulting in micropore filling at very low $p / \mathrm{p}^{\circ}$. All curves exhibited type I isotherm, which implies a near absence of external surface for further adsorption.

\section{Effect of Deashing Treatment on the Surface Morphology of Activated Carbon}

Scanning electron micrographs of raw material, activated carbon, and activated carbon derived from post-treatment included the $\mathrm{H}_{3} \mathrm{PO}_{4}$, distilled water, and ultrasonication are illustrated in Figs. 3, 4, 5, and 6, respectively.

Figure 3a presents the micrographs for the CS raw material. Its surface was dense and planar without any cracks and crevices. This would account for its poor or negligible BET surface area (Table 3). As shown in Fig. 3a, the surface of raw material CS with holes that were spaced out on the surface have smooth edges. Most of the pores of the CS were closed up at the magnification of the SEM. Endocarp biomass types such as CS exhibit significantly higher bulk density and hardness due to their high cellular density. The high bulk density corresponds to low porosity. This explains its non-porous structure. Moreover, two-stage continuous physical activation uncovered mesopores and micropores that were previously covered/clogged and simultaneously created new pores by selective burning off the carbon atoms (Fig. 3b). However, some impurities and unclear pores were still present on the surface of the activated carbon. The presence of the impurities and ash led to the low surface area and low adsorption for the activated carbon.

The morphology of activated carbon prepared under $\mathrm{H}_{3} \mathrm{PO}_{4}$ post-treatment is displayed in Fig. 4. In all cases, there was a rough appearance by the dehydrating effect of $\mathrm{H}_{3} \mathrm{PO}_{4}$. There was an increase of pore blockage and a decrease in pore structure due to the drastic reaction of the chemical reagent. Before those residual ash could be washed out from the pores with $\mathrm{H}_{3} \mathrm{PO}_{4}$ solution, the walls between adjacent pores could have been collapsed. This effect was more evident in samples treated with $\mathrm{H}_{3} \mathrm{PO}_{4}$ with higher temperature. The surface area of the $\mathrm{CS}$ activated carbon post treated via $\mathrm{H}_{3} \mathrm{PO}_{4}$ was melted, and the pores were no longer visible, as shown in Figs. $4 \mathrm{~b}$ and $4 \mathrm{c}$. The low surface area also can be attributed to the pore blockage on the adsorbent surface by the remaining chemical agent (Yunus et al. 2020). Post-treatment via $\mathrm{H}_{3} \mathrm{PO}_{4}$ was unable to promote further deashing, which might be due to the insulating layer formation on the adsorbent surface (Li et al. 2016; Peng et al. 2018). This study shows that $\mathrm{H}_{3} \mathrm{PO}_{4}$ post-treatment 
affected the interior cell walls and the pore structure of activated carbon. This supports the results of the iodine number for activated carbon prepared via $\mathrm{H}_{3} \mathrm{PO}_{4}$ post-treatment being lower than the other activated carbon. There were numerous cracks distributed over the surface, indicating the severe interaction of the $\mathrm{H}_{3} \mathrm{PO}_{4}$ with the CS during post-treatment. The drastic change on the carbon surface had resulted a low adsorption capability and surface area to the CS activated carbon.

The SEM analysis suggested that deashing via distilled water was effective to produce high porosity for CS activated carbon (Fig. 5). When the post-treatment temperature was increased from room temperature to $60{ }^{\circ} \mathrm{C}$, the pore development in CS activated carbon increased (Fig. 5b). CS activated carbon post-treated with $60{ }^{\circ} \mathrm{C}$ distilled water adopted a regular arrangement of pores with well-arranged holes and smooth walls. As stated by Gisi et al. (2016), distilled water removes dirt, dust, and other surface impurities from the activated carbon. Furthermore, activated carbon post-treated with distilled water had a regular and highly micro-porous surface, indicating relatively high surface area. The surface area of the CS activated carbon post-treated with $60{ }^{\circ} \mathrm{C}$ distilled water was highly enhanced by the presence of smaller pores, which can hold smaller particles from solution during adsorption. This observation is supported by BET surface area of the CS activated carbon, as illustrated in Table 3. CS activated carbon gained the highest BET surface area when it was post-treated via distilled water. However, it is noteworthy that $\mathrm{CS}$ activated carbon has low performance (less porous) when post-treated at high temperature $\left(100^{\circ} \mathrm{C}\right)($ Fig. $5 \mathrm{c})$. 


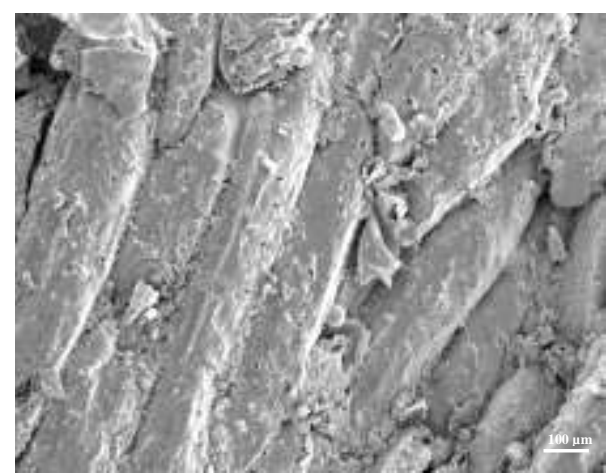

(a) Raw Material

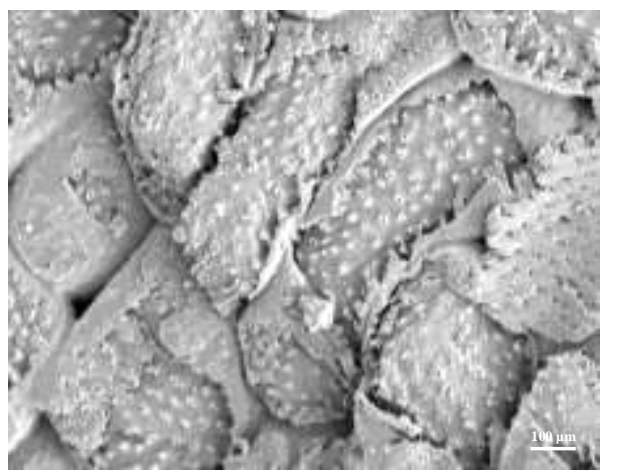

(b) Activated Carbon

Fig. 3. Scanning electron micrograph of raw material and activated carbon at $1000 x$ magnification

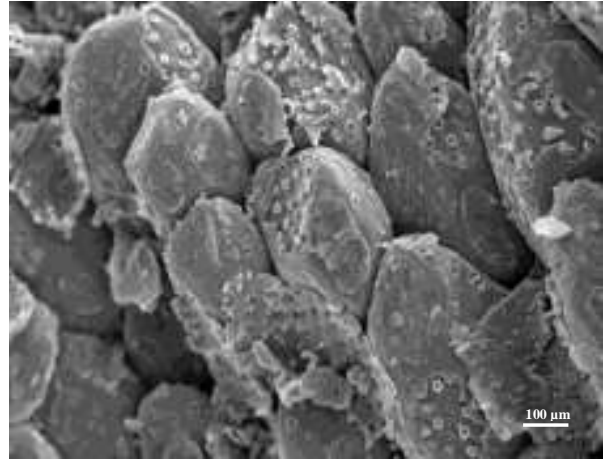

(a) Temperature: RT

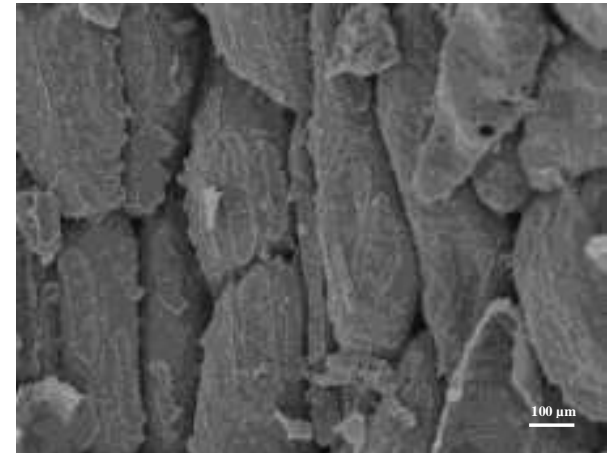

(b) Temperature: $60^{\circ} \mathrm{C}$

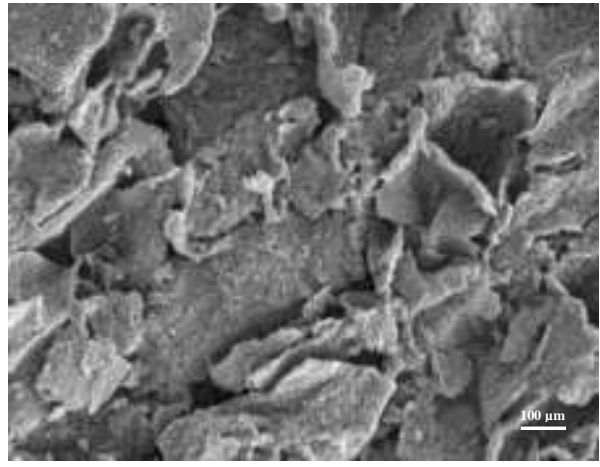

(c) Temperature: $100^{\circ} \mathrm{C}$

Fig. 4. Scanning electron micrograph of $\mathrm{H}_{3} \mathrm{PO}_{4}$ post-treated activated carbon at 1000 x magnification 


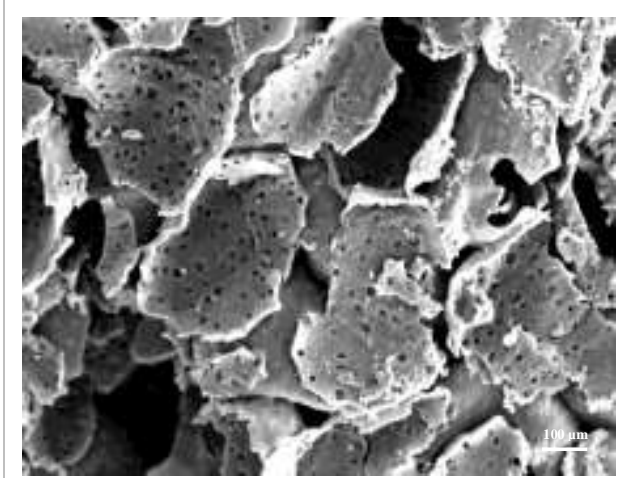

(a) Temperature: RT

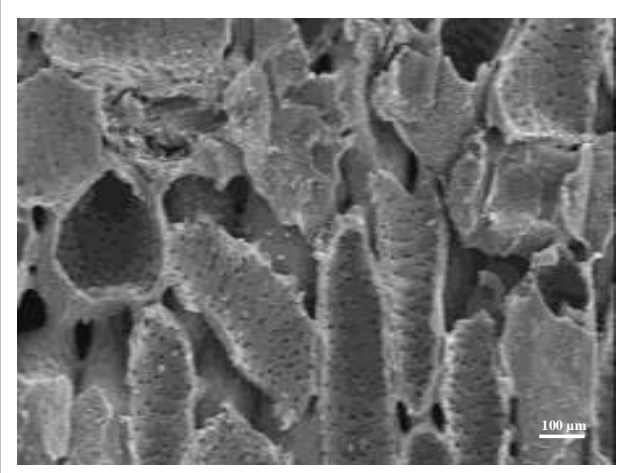

(b) Temperature: $60^{\circ} \mathrm{C}$

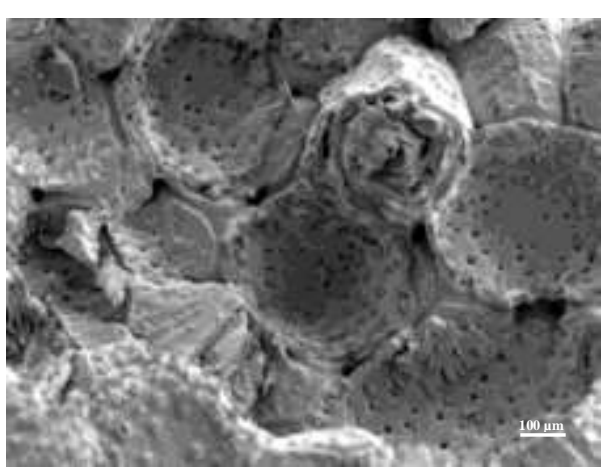

(c) Temperature: $100^{\circ} \mathrm{C}$

Fig. 5. Scanning electron micrograph of distilled water post-treated activated carbon at 1000x magnification

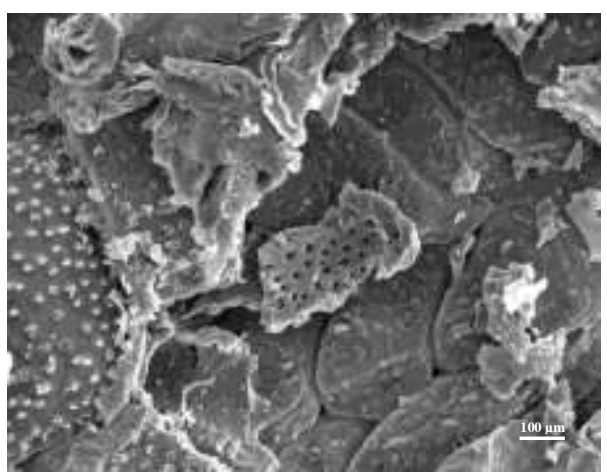

(a) Temperature: RT

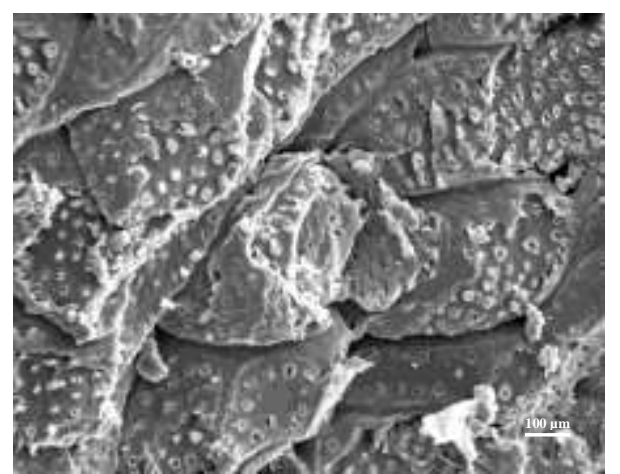

(b) Temperature: $60^{\circ} \mathrm{C}$

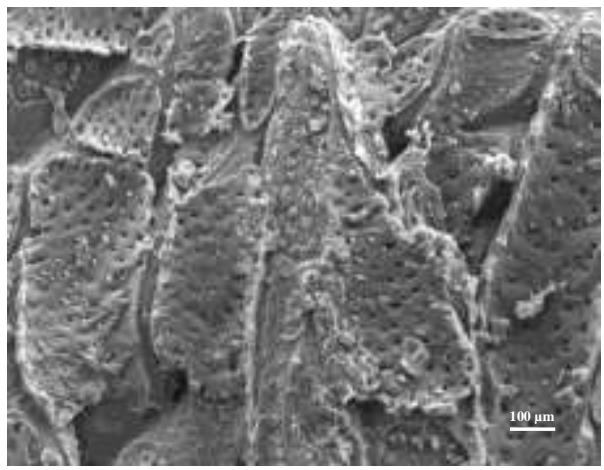

(c) Temperature: $80^{\circ} \mathrm{C}$

Fig. 6. Scanning electron micrograph of ultrasonic post-treated activated carbon at 1000x magnification 
Effects of ultrasound post-treatment on CS activated carbon is shown in Fig. 6. This experiment further manifests the capability of ultrasonic treatment to penetrate deeper into the structure of CS activated carbon, creating cavity and pores, thus increasing the surface area. The high surface area may be due to the vibrating effect from ultrasonic posttreatment. The collapse of the bubbles generates enormous energy. The generated shock waves contribute to the removal efficiency. As shown in Fig. 4b, the inorganic impurities adhered to the untreated activated carbon in a rigid as well as loose manner. These impurities were removed by ultrasonic post-treatment, as shown in Fig. 6a. That image shows a number of unfilled cavities. It is apparent that the unfilled cavities were due to removal of ash material by ultrasonic treatment. However, there was a noticeable increase of pore size on the CS activated when the ultrasonic temperature increased from room temperature to $60{ }^{\circ} \mathrm{C}$ (Fig. $6 \mathrm{~b}$ to $6 \mathrm{c}$ ). The increased pore size was very well correlated with the reduction of surface area. Surface area and volume decreased, while the diameter of the pore increased, indicating the reduction of available micropore and mesopore volumes (Cheng et al. 2016; Boruah et al. 2019). The increasing pore size on the CS activated carbon caused the reduction of surface area when the impregnation temperature increased from room temperature to $60{ }^{\circ} \mathrm{C}$. During ultrasonication, liquid macroscopic turbulence and high velocity collisions between solid particles in the deashing system are produced by the micro jet, shock wave, acoustic streaming, and other mechanical effects (Li et al. 2018). Ultrasonication is a harsher deashing treatment than the other treatments applied in this study. With the high capabilities to remove rigid impurities, ultrasonic deashing is highly suggested for porosity and microarchitecture refining of activated carbon with higher abrasion number such as palm kernel shell (Lee 2019).

\section{Elemental Analysis of Raw Material and Distilled Water Post-Treated Activated Carbon}

The EDXRF evaluation of raw material, activated carbon, and the CS activated carbon post-treated via distilled water at $60{ }^{\circ} \mathrm{C}$ is shown in Table 4. The raw material contained a high amount of potassium. A notable characteristic of solid biomass as compared to coal is their significantly higher potassium content. Biomass contain variable proportions of potassium, a key plant nutrient, and this is one of the more significant components affecting ash behaviour (Mason et al. 2017). Biomass with high potassium contents react with other ash forming elements (i.e. $\mathrm{Cl}, \mathrm{Si}, \mathrm{P}$, and $\mathrm{S}$ ) and lead to different ash related operational problems (Wang et al. 2012). Major ash forming elements such as $\mathrm{Ca}, \mathrm{K}$, and $\mathrm{Si}$ are of relevance for the ash melting behaviour and deposit formation (Chin et al. 2018). The ash forming elements tend to influence the formation and characteristics of the ash. 
Table 4. EDXRF Analysis for Raw Material, Activated carbon, and Distilled Water Post-Treated Carbon

\begin{tabular}{|c|c|c|c|}
\hline $\begin{array}{c}\text { Element in } \\
\text { Oxide }\end{array}$ & Raw Material & Activated Carbon & $\begin{array}{c}\text { Distilled Water Post- } \\
\text { treatment }\end{array}$ \\
\hline $\mathrm{SiO}_{2}$ & 3.75 & - & - \\
\hline $\mathrm{P}_{2} \mathrm{O}_{5}$ & 1.16 & 65.74 & 64.36 \\
\hline $\mathrm{MgO}$ & - & - & - \\
\hline $\mathrm{SO}_{3}$ & 15.48 & 16.61 & 30.68 \\
\hline $\mathrm{K}_{2} \mathrm{O}$ & 29.89 & 8.65 & 0.79 \\
\hline $\mathrm{CaO}$ & 23.06 & 4.61 & 3.59 \\
\hline $\mathrm{TiO}_{2}$ & 0.46 & 0.25 & 0.29 \\
\hline $\mathrm{CrO}_{\mathrm{MnO}}$ & 0.11 & 0.08 & 0.04 \\
\hline $\mathrm{Fe} \mathrm{O}_{3}$ & 0.22 & 0.07 & - \\
\hline $\mathrm{NiO}$ & 9.42 & 1.99 & 0.14 \\
\hline $\mathrm{CuO}_{2 n O}$ & 0.04 & - & 0.01 \\
\hline $\mathrm{ZnO}$ & 0.82 & 0.08 & 0.04 \\
\hline $\mathrm{Dy}_{2} \mathrm{O}_{3}$ & 8.90 & 0.04 & 0.06 \\
\hline
\end{tabular}

The increase of ash content of the activated carbon was caused by the oxidation reaction during the physical activation, which reduced the adsorption capabilities. This is mainly due to pores clogged by various minerals including $\mathrm{Ca}$ and $\mathrm{K}$. The deposition of minerals on the surface of activated carbon was also reported by Sukoyo et al. (2019). As noted by Husillos Rodríguez et al. (2016), the largest components found in activated carbon ash were $\mathrm{Si}, \mathrm{Fe}$, and $\mathrm{S}$. The EDXRF result reveals that distilled water post treatment decreased the ash forming elements including $\mathrm{Fe}, \mathrm{K}$, and $\mathrm{Ca}$. The deashing post-treatment reduced the proportion of the ash forming elements. The result shows that the Fe mineral was highly reduced via the deashing post-treatment. According to Wise et al. (2016), deposited Fe blocks pores, thereby reducing catalyst activity. Additionally, $\mathrm{Fe}_{2} \mathrm{O}_{3}$ blocks the inner pores of activated carbon (Santos et al. 2015). Deashing via distilled water decreased the Fe particles from the CS activated carbon.

Amongst all elements, $\mathrm{Fe}_{2} \mathrm{O}_{3}$ and $\mathrm{SiO}_{2}$ are the hardest substances to remove (Madakson et al. 2012). There was $100 \%$ reduction of the $\mathrm{SiO}_{2}$ in $\mathrm{CS}$ activated carbons during the distilled water deashing process. This result is in good agreement with the physiochemical result for this present work. As stated by Maulina and Iriansyah (2018), a higher silica content result in a higher ash content in the adsorbent. The low concentration of $\mathrm{SiO}_{2}$ contributed to the low amount of ash content in the CS activated carbon (Table 1). The results indicate that post-treatment with distilled water led to microporous activated carbon with superior physical characteristics.

\section{CONCLUSIONS}

1. A high amount of ash was successfully removed through the post-treatment. Ash forming elements including $\mathrm{Fe}, \mathrm{K}$, and $\mathrm{Ca}$ are broadly reduced from the CS activated carbon.

2. Distilled water deashing process was more efficient in enhancing the micropore volume 
of CS activated carbon, as $80 \%$ of the total pore ratio was occupied with micropores.

3. Post-treatment with distilled water produced a commercial grade activated carbon with superior physical characteristics included high yield, high fixed carbon content, and maximum adsorption capability.

4. Ultrasonic treatment penetrated deeper into the structure of CS activated carbon, creating cavities and pores, which increased the surface area. Ultrasonic deashing treatment is highly suggested for porosity and microarchitecture refining of activated carbon with high abrasion number to withstand harsher treatment from ultrasonic deashing process.

\section{ACKNOWLEDGMENTS}

The authors are grateful for the financial support given by the Malaysia Ministry of Education through the Higher Institution Centre of Excellence (HICoE) program at the Institute of Tropical Forestry and Forest Products (INTROP). The authors also sincerely thank the postgraduate students that participated in this research.

\section{REFERENCES CITED}

Abechi, S. E., Gimba, C. E., Uzairu, A., and Dallatu, Y. A. (2013). "Preparation and characterization of activated carbon from palm kernel shell by chemical activation," Research Journal of Chemical Sciences 3(7), 54-61.

Ahiduzzaman, M., and Islam, A. K. M. S. (2016). "Preparation of porous bio-char and activated carbon from rice husk by leaching ash and chemical activation," SpringerPlus 5(1), 1248. DOI: 10.1186/s40064-016-2932-8

Anisuzzaman, S. M., Joseph, C. G., Daud, W. M. A. B. W., Krishnaiah, D., and Yee, H. S. (2015). "Preparation and characterization of activated carbon from Typha orientalis leaves," International Journal of Industrial Chemistry 6(1), 9-21. DOI: $10.1007 / \mathrm{s} 40090-014-0027-3$

Arenas, E., and Chejne, F. (2004). "The effect of the activating agent and temperature on the porosity development of physically activated coal chars," Carbon 42, 2451-2455. DOI: $10.1016 /$ j.carbon.2004.04.041

Babatunde, O. A., Garba, S., and Ali, Z. N. (2016). "Surface modification of activated carbon for improved iodine and carbon tetrachloride adsorption," American Journal of Chemistry 6(3), 74-79. DOI: 10.5923/j.chemistry.20160603.02

Baseri, J. R., Palanisamy, P. N., and Sivakumar, P. (2012). "Preparation and characterization of activated carbon from Thevetia peruviana for the removal of dyes from textile waste water," Advances in Applied Science Research 3(1), 377-383.

Boruah, A., Rasheed, A., Mendhe, V. A., and Ganapathi, S. (2019). "Specific surface area and pore size distribution in gas shales of Raniganj Basin, India," Journal of Petroleum Exploration and Production Technology 9(2), 1041-1050. DOI: 10.1007/s13202-018-0583-8

Chen, Y., Huang, B., Huang, M., and Cai, B. (2011). "On the preparation and characterization of activated carbon from mangosteen shell," Journal of the Taiwan 
Institute of Chemical Engineers 42(5) 837-842. DOI: 10.1016/j.jtice.2011.01.007

Cheng, S., Zhang, L., Xia, H., Peng, J., Shu, J., and Li, C. (2016). "Ultrasound and microwave-assisted preparation of Fe-activated carbon as an effective low-cost adsorbent for dyes wastewater treatment," RSC Advances 6(82), 78936-78946. DOI: 10.1039/C6RA14082C

Chin, K. L., H'ng, P. S., Maminski, M., Go, W. Z., Lee, C. L., Raja-Nazrin, R. A., Khoo, P. S., Ashikin, S. N., and Halimatun, I. (2018). "Additional additives to reduce ash related operation problems of solid biofuel from oil palm biomass upon combustion," Industrial Crops and Products 123, 285-295. DOI: 10.1016/j.indcrop.2018.06.081

Chin, K. L., H'ng, P. S., Paridah, M. T., Szymona, K., Maminski, M., Lee, S. H., Lum, W. C., Nurliyana, M. Y., Chow, M. J., and Go, W. Z. (2015). "Reducing ash related operation problems of fast growing timber species and oil palm biomass for combustion applications using leaching techniques," Energy 90, 622-630.

Gerçel, Ö., Gerçel, H. F., Koparal, A. S., and Öğütveren, Ü. B. (2008). "Removal of disperse dye from aqueous solution by novel adsorbent prepared from biomass plant material," Journal of Hazardous Materials 160(2-3), 668-674. DOI: 10.1016/j.jhazmat.2008.03.039

Gisi, S. De, Lofrano, G., Grassi, M., and Notarnicola, M. (2016). "Characteristics and adsorption capacities of low-cost sorbents for wastewater treatment: A review," Sustainable Materials and Technologies 9, 10-40. DOI:

10.1016/j.susmat.2016.06.002

Goswami, S. (2015). "Impact of coal mining on environment," Russian Federation European Researcher 92(3), 185-196. DOI: 10.13187/er.2015.92.185

Hagemann, N., Spokas, K., Schmidt, H. P., Kägi, R., Böhler, M. A., and Bucheli, T. D. (2018). "Activated carbon, biochar and charcoal: Linkages and synergies across pyrogenic carbon's ABCs," Water 10(2), 1-19. DOI: 10.3390/w10020182

Hamasaki, A., Furuse, A., Sekinuma, Y., Fujio, K., Iide, M., and Ozeki, S. (2019). "Improving the micropore capacity of activated carbon by preparation under a high magnetic field of 10 T," Scientific Reports 9(1), 1-11. DOI: 10.1038/s41598-01943818-y

Haykiri-Acma, H., and Yaman, S. (2019). "Effects of dilute phosphoric acid treatment on structure and burning characteristics of lignocellulosic biomass," Journal of Energy Resources Technology 141, 1-8. DOI: 10.1115/1.4042719

Husillos Rodríguez, N., Martínez-Ramírez, S., and Blanco-Varela, M. T. (2016).

"Activated carbon as an alternative fuel. Effect of carbon ash on cement clinkerization," Journal of Cleaner Production 119, 50-58. DOI:

10.1016/j.jclepro.2016.01.093

Jayaraman, S., Jain, A., Ulaganathan, M., Edison, E., Srinivasan, M. P., Balasubramanian, R., Aravindan, V., and Madhavi, S. (2017). "Li-ion vs. Na-ion capacitors: A performance evaluation with coconut shell derived mesoporous carbon and natural plant based hard carbon," Chemical Engineering Journal 316, 506-513. DOI: 10.1016/j.cej.2017.01.108

Kawasaki, H., Takeda, Y., and Arakawa, R. (2007). "Mass spectrometric analysis for high molecular weight synthetic polymers using ultrasonic degradation and the mechanism of degradation," Analytical Chemistry 79(11), 4182-4187. DOI: $10.1021 / \mathrm{ac} 062304 \mathrm{v}$

Kilpimaa, S., Runtti, H., Kangas, T., Lassi, U., and Kuokkanen, T. (2014). "Removal of 
phosphate and nitrate over a modified carbon residue from biomass gasification," Chemical Engineering Research and Design 92(10), 1923-1933. DOI:

10.1016/j.cherd.2014.03.019

Koda, S., Miyamoto, M., Toma, M., Matsuoka, T., and Maebayashi, M. (2009).

"Inactivation of Escherichia coli and Streptococcus mutans by ultrasound at 500 kHz," Ultrasonics Sonochemistry 16(5), 655-659. DOI:

10.1016/j.ultsonch.2009.02.003

Kumar, A., and Jena, H. M. (2016). "Preparation and characterization of high surface area activated carbon from fox nut (Euryale ferox) shell by chemical activation with $\mathrm{H}_{3} \mathrm{PO}_{4}$," Results in Physics 6, 651-658. DOI: 10.1016/j.rinp.2016.09.012

László, K., Bóta, A., and Nagyu, L. G. (1997). "Characterization of activated carbons from waste materials by adsorption from aqueous solutions," Carbon 35(5), 593-598. DOI: 10.1016/S0008-6223(97)00005-5

Lee, C. L., H'ng, P. S., Chin, K. L., Paridah, M. T., Rashid, U., and Go, W. Z. (2019). "Characterization of bioadsorbent produced using incorporated treatment of chemical and carbonization procedures," Royal Society Open Science 6(9), 190667. DOI: 10.1098/rsos. 190667

Lee, C. L., H’ng, P. S., Chin, K. L., Paridah, M. T., Rashid, U., Maminski, M., Go, W. Z., Nazrin, R. A. R., Rosli, S. N. A., and Khoo, P. S. (2018). "Production of bioadsorbent from phosphoric acid pretreated palm kernel shell and coconut shell by two-stage continuous physical activation via $\mathrm{N}_{2}$ and air," Royal Society Open Science 5(12), 180775. DOI: 10.1098/rsos.180775

Lee, C. L., H'ng, P. S., Paridah, M. T., Chin, K. L., Khoo, P. S., Nazrin, R. A. R., Asyikin, S. N., and Mariusz, M. (2017). "Effect of reaction time and temperature on the properties of carbon black made from palm kernel and coconut shell," Asian Journal of Scientific Research 10(1), 24-33. DOI: 10.3923/ajsr.2017.Research

Li, M., Li, J., and Zhu, C. (2018). "Effect of ultrasound pretreatment on enzymolysis and physicochemical properties of corn starch," International Journal of Biological Macromolecules 111, 848-856. DOI: 10.1016/j.ijbiomac.2017.12.156

Li, M., Ma, S., and Zhu, X. (2016). "Preparation of activated carbon from pyrolyzed rice husk by leaching out ash content after $\mathrm{CO}_{2}$ activation," BioResources 11(2), 33843396. DOI: 10.15376/biores.11.2.3384-3396

Li, Y. h., Chang, F. m., Huang, B., Song, Y. p., Zhao, H. y., and Wang, K. j. (2020). "Activated carbon preparation from pyrolysis char of sewage sludge and its adsorption performance for organic compounds in sewage," Fuel 266, 117053. DOI: 10.1016/j.fuel.2020.117053

Lima, I. M., and Marshall, W. E. (2005). "Granular activated carbons from broiler manure : physical , chemical and adsorptive properties," Biomass and Bioenergy 96, 699-706. DOI: 10.1016/j.biortech.2004.06.021

Liu, X., He, C., Yu, X., Bai, Y., Ye, L., Wang, B., and Zhang, L. (2018). "Net-like porous activated carbon materials from shrimp shell by solution-processed carbonization and $\mathrm{H}_{3} \mathrm{PO}_{4}$ activation for methylene blue adsorption," Powder Technology 326, 181-189. DOI: 10.1016/j.powtec.2017.12.034

López, Y., García, A., Karimi, K., Taherzadeh, M. J., and Martín, C. (2010). “Chemical characterisation and dilute-acid hydrolysis of rice hulls from an artisan mill," BioResources 5(4), 2268-2277. DOI: 10.15376/biores.5.4.2268-2277

Madakson, P. B., Yawas, D. S., and Apasi, A. (2012). "Characterization of coconut chell 
ash for potential utilization in metal matrix composites for automotive applications," International Journal of Engineering Science and Technology 4(03), 1190-1198.

Mason, P. E., Jones, J. M., Darvell, L. I., and Williams, A. (2017). "Gas phase potassium release from a single particle of biomass during high temperature combustion," Proceedings of the Combustion Institute 36(2), 2207-2215. DOI:

10.1016/j.proci.2016.06.020

Maulina, S., and Iriansyah, M. (2018). "Characteristics of activated carbon resulted from pyrolysis of the oil palm fronds powder," in: IOP Conference Series: Materials Science and Engineering, Sumatera Utara, Indonesia. DOI: 10.1088/1757899X/309/1/012072

Mesa, A. C., and Spokas, K. A. (2016). "Impacts of biochar (black carbon) additions on the sorption and efficacy of herbicides," in: Herbicides and Environment, A. Kortekamp (ed.), INTECH Open Access Publisher, London, pp. 315-340. DOI: $10.5772 / 13620$

Nsami, J. N., and Mbadcam, J. K. (2013). "The adsorption efficiency of chemically prepared activated carbon from cola nut shells by $\mathrm{ZnCl}_{2}$ on methylene blue," Journal of Chemistry 2013, Article ID 469170. DOI: 10.1155/2013/469170

Pandey, A., Bhaskar, T., Stöcker, M., and Sukumaran, R. (Eds.). (2015). Recent advances in Thermochemical Conversion of Biomass, Elsevier.

Peng, X., Hu, F., Zhang, T., Qiu, F., and Dai, H. (2018). "Amine-functionalized magnetic bamboo-based activated carbon adsorptive removal of ciprofloxacin and norfloxacin : A batch and fixed-bed column study," Bioresource Technology 249, 924-934. DOI: 10.1016/j.biortech.2017.10.095

Robinson, T., McMullan, G., Marchant, R., and Nigam, P. (2001). "Remediation of dyes in textile effluent: A critical review on current treatment technologies with a proposed alternative," Bioresource Technology 77(3), 247-255. DOI: 10.1016/S09608524(00)00080-8

Ronsse, F., Van Hecke, S., Dickinson, D., and Prins, W. (2013). "Production and characterization of slow pyrolysis biochar: Influence of feedstock type and pyrolysis conditions," GCB Bioenergy 5(2), 104-115. DOI: 10.1111/gcbb.12018

Roquerol, F., Rouquerol, J., and Sing, K. (2013). Adsorption by Powders and Solids: Principles, Methodology, and Applications, Elsevier, Amsterdam.

Saleem, J., Shahid, U. Bin, Hijab, M., Mackey, H., and McKay, G. (2019). "Production and applications of activated carbons as adsorbents from olive stones," Biomass Conversion and Biorefinery 9(4), 775-802. DOI: 10.1007/s13399-019-00473-7

Sana, H., Rahim, M. U., and Munir, S. (2018). "Effect of complexing agents on desulphurization and deashing of coal by $\mathrm{H}_{2} \mathrm{O}_{2} / \mathrm{H}_{2} \mathrm{SO}_{4}$ leaching," Energy \& Environment, 0958305X18769870. DOI: 10.1177/0958305X18769870

Santos, V. P., Wezendonk, T. A., Jaén, J. J. D., Dugulan, A. I., Nasalevich, M. A., Islam, H. U., Chojecki, A., Sartipi, S., Sun, X., Hakeem, A. A., Koeken, A. C. J., Ruitenbeek, M., Davidian, T., Meima, G. R., Sankar, G., Kapteijn, F., Makkee, M., and Gascon, J. (2015). "Metal organic framework-mediated synthesis of highly active and stable Fischer-Tropsch catalysts," Nature Communications 6, 6451. DOI: $10.1038 /$ ncomms 7451

Siipola, V., Tamminen, T., Källi, A., Lahti, R., Romar, H., Rasa, K., Keskinen, R., Hyväluoma, J., Hannula, M., and Wikberg, H. (2018). "Effects of biomass type, carbonization process, and activation method on the properties of bio-based activated 
carbons," BioResources 13(3), 5976-6002. DOI: 10.15376/biores.13.3.5976-6002

Singh, B. (2013). "Study on pollution of water and soil due to copper mining in Khetari copper mine project," International Journal of Research in Science and Technology, 2(VI).

Sukoyo, A., Djoyowasito, G., and Wibisono, Y. (2019). "Unravelling the potency of pactivated carbon Powder derived from cultivated marine microalgae as a promising filler in mixed matrix membranes," AgriEngineering 1(2), 188-204. DOI:

10.3390/agriengineering 1020014

Sych, N. V., Trofymenko, S. I., Poddubnaya, O. I., Tsyba, M. M., Sapsay, V. I., Klymchuk, D. O., and Puziy, a. M. (2012). "Porous structure and surface chemistry of phosphoric acid activated carbon from corncob," Applied Surface Science 261, 75 82. DOI: 10.1016/j.apsusc.2012.07.084

Tan, I. A. W., Abdullah, M. O., Lim, L. L. P., and Yeo, T. H. C. (2017). "Surface modification and characterization of coconut shell-based activated carbon subjected to acidic and alkaline treatments," Journal of Applied Science Research \& Process Engineering 4(2), 186-194.

Thwe, L. K., Phyo, S. W., and Khin, T. N. (2018). "Effectiveness of prepared corn husk activated carbon on the abatement of sodium chloride content in fish sauce," Universal Journal of Agricultural Research 6(2), 91-97. DOI: 10.13189/ujar.2018.060206

Tiwari, R. (2017). "Activated carbon market growing at a CAGR of $9.4 \%$ during 2016 to 2021," PR Newswire India, Pune.

Tsai, W. T., and Jiang, T. J. (2018). "Mesoporous activated carbon produced from coconut shell using a single-step physical activation process," Biomass Conversion and Biorefinery 8(3), 711-718. DOI: 10.1007/s13399-018-0322-X

Wang, J., Xing, P., Du, X., Luo, X., Zhuang, Y., Lyu, T., and Dong, X. (2017). “Kinetics analysis and effects of various factors on removing iron from silica sand under ultrasound-assistance," Silicon 9(2), 265-272. DOI: 10.1007/s12633-016-9427-7

Wang, L., Hustad, E., and Skreiberg, Ø. (2012). "A critical review on additives to reduce ash related operation problems in biomass combustion applications," Energy Procedia 20 (1876), 20-29. DOI: 10.1016/j.egypro.2012.03.004

Wang, S., Boyjoo, Y., Choueib, A., and Zhu, Z. H. (2005). "Removal of dyes from aqueous solution using fly ash and red mud," Water Research 39(1), 129-138. DOI: 10.1016/j.watres.2004.09.011

Wang, X., Li, D., Li, W., Peng, J., Xia, H., Zhang, L., Guo, S., and Chen, G. (2013). "Optimization of mesoporous activated carbon from coconut shells by chemical activation with phosphoric acid," BioResources 8(4), 6184-6195. DOI: 10.15376/biores.8.4.6184-6195

Wise, A. M., Weker, J. N., Kalirai, S., Farmand, M., Shapiro, D. A., Meirer, F., and Weckhuysen, B. M. (2016). "Nanoscale chemical imaging of an individual catalyst particle with soft X-ray ptychography," ACS Catalysis 6(4), 2178-2181. DOI: 10.1021/acscatal.6b00221

Yacob, A. R., and Al Swaidan, H. M. (2012). "Phosphoric acid effect on prepared activated carbon from Saudi Arabia's date frond waste," Applied Mechanics and Materials 110-116, 2124-2130. DOI: 10.4028/www.scientific.net/AMM.110116.2124

Yenisoy-Karakaş, S., Aygün, A., Güneş, M., and Tahtasakal, E. (2004). "Physical and 
chemical characteristics of polymer-based spherical activated carbon and its ability to adsorb organics," Carbon 42(3), 477-484. DOI: 10.1016/j.carbon.2003.11.019

Zhang, M., Li, Y., Si, H., Wang, B., and Song, T. (2017). "Preparation and electrochemical performance of coconut shell activated carbon produced by the $\mathrm{H}_{3} \mathrm{PO}_{4}$ activation with rapid cooling method," International Journal of Electrochemical Science 12(8), 7844-7852. DOI: 10.20964/2017.08.37

Zulkania, A., Hanum, G. F., and Sri Rezki, A. (2018). "The potential of activated carbon derived from bio-char waste of bio-oil pyrolysis as adsorbent," MATEC Web of Conferences 154, 1-6. DOI: 10.1051/matecconf/201815401029

Article submitted: 22 May 2020; Peer review completed: August 3, 2020; Revised version received and accepted: August 13, 2020; Published: August 27, 2020.

DOI: $10.15376 /$ biores. 15.4.7749-7769 